Technical Note

\title{
Cultural Heritage and Communication through Simulation Videogames-A Validation of Minecraft
}

\author{
Jorge Garcia-Fernandez ${ }^{1, *(1)}$ and Leonor Medeiros ${ }^{2}(\mathbb{D}$ \\ 1 Faculty of Architecture, University of Lisbon Rua.Sa-Nogeira, University Campus, 1349-055 Lisbon, Portugal \\ 2 Faculty of Social and Human Sciences, New University of Lisbon, Avenida Berna 26 C, \\ 1069-061 Lisbon, Portugal \\ * Correspondence: jorgefernandez@fa.ulisboa.pt
}

Received: 23 May 2019; Accepted: 30 July 2019; Published: 1 August 2019

\begin{abstract}
The use of world-simulation videogames for cultural heritage $(\mathrm{CH})$ communication presents one of the greatest opportunities for engaging people with the safeguarding of cultural resources. However, not all simulation videogames have the capacity to transmit heritage values efficiently. This article reviews the use of serious and commercial videogames in $\mathrm{CH}$ to frame and properly identify characteristics for the selection and assessment of videogames in the context of cultural communication. Based on the analysis of the capacities of videogames to motivate, immerse and represent reality, the videogame Minecraft is identified as one of the optimal solutions to represent and promote engagement with the cultural built environment. As such, the authors assessed the capacity of the videogame Minecraft to be used as an efficient tool to communicate built heritage environments, considering identified criteria on immersion, motivation, and fidelity on simulation.
\end{abstract}

Keywords: cultural heritage; communication; motivation; videogames; Minecraft

\section{Introduction}

The preservation of our cultural resources is a cornerstone in the safeguard of values that identify us as individuals and as social groups, while fostering a sense of belonging [1,2]. These resources are also a vital asset in cultural, economic, and educational areas, providing content and context to many key daily activities. Regardless, they suffer deterioration, destruction, or dramatic alterations, under natural and human factors, especially the built heritage and particularly the smaller and not-so-recognized heritage, such as vernacular architecture or industrial heritage. But, in today's society, communication for the preventive preservation of built heritage is supported by the progress in the field of Digital Heritage (DH) [3], and specially by the development of the production and management of 3D information of cultural heritage $(\mathrm{CH})$, increasingly accessible on online platforms. Its implementation has proficiently hosted and boosted interactions between people and $\mathrm{CH}$ sites around the world, regardless of their location, allowing the creation of "online windows" through time and space $[4,5]$.

Within the field of $\mathrm{DH}$, real world-simulation videogames represent a strong opportunity to engage communities with the protection and revalorization of cultural heritage assets. Studies such as [6-8], have demonstrated its capacity to transmit cultural values and raise awareness of cultural preservation in a highly engaging environment. However, in practice, simulation videogames do not always fit our requests in terms of cultural heritage communication-often they do not accurately represent the built environment geometrically or semantically, they do not promote interaction and learning between the virtual world and gamers, they do not include cooperation mechanics between users (interplayer cooperation) towards a preservation goal, or they use the heritage sites merely as a stage. 
Without such capacities, we are left with inadequate knowledge that limits the scope and efficiency of heritage communication for the preservation of our cultural resources, namely built heritage.

To address these questions, this paper begins with an introduction to heritage communication based on world-simulation videogames and a review of videogames in heritage communication, exploring the uses of both serious and commercial videogames. We then explored the state-of-the-art of commercial simulation videogames in terms of their capacity for use in cultural heritage. Based on these defined elements, to consider in the use of videogames in heritage communication, it is further examined the feasibility of Minecraft as an efficient simulation videogame for public communication purposes.

\section{Heritage Communication Based on World-Simulation Videogames}

In contrast with the traditional postures that give privilege to monumentality and expertise within the western narrative of heritage $[9,10]$, our premises on the communication of built heritage support the idea of multi-dimensionality in heritage (ranging from individual, local, and global) and its role in promoting the interactivity between communities and culture, opening the practice to other types of heritage, other voices, and multiple knowledge systems [11].

The new century has brought new communication needs and new tools to facilitate it widely and more efficiently, especially the exponential evolution of digital technology and the new communication channels it has facilitated. When referring to cultural heritage $(\mathrm{CH})$, communication holds high potential for "encouraging greater participation, innovation, and creativity in learning" [12], and even in the mitigation of functional illiteracy [13], especially through the interactive and autonomous tools brought by web 2.0 that allow the user to also be a creator of content.

Digital Technologies in $\mathrm{CH}$ have opened the door for new types of interactions, promoting an horizontal communication based on a dialogical model, and shortening the distance (physically and intellectually) between the public and heritage assets, while lowering associated costs [14], therefore reconfiguring the ways transmission and reception of information about heritage is achieved. This has been supporting the idea of "integral heritage", which sees not just the sites isolated and managed independently, but which connects objects, sites, landscapes, and intangible heritage in a systemic view. In many ways, the built heritage and the architecture, as a place created for life to unfold, can be a powerful anchor to connect other dimensions of heritage, and, as platforms like Minecraft show, the creation of a place is a first step for a story (or history) to unfold virtually.

Cultural heritage informatics has been empowered with the tools to handle an integral cultural reality, connect different dimensions of heritage, and make use of a complex range of digital technologies, from remote sensing technologies for as-built data creation to social media for reaching several new audiences [15]. Progresses on digital heritage communication, taking advantage of internet and social networks reinforce the idea of interconnectivity, and mobile and desktop processing capacities have taken access to content and personalized handling further $[16,17]$. These lead to enhanced interaction, deeper immersion and the possibility of personalization by different audiences and different individuals, allowing for personalized experiences and customized learning. The effective communication of $\mathrm{CH}$ in these new online platforms allows us to virtually experience the historic contents of remote places, in geographies often inaccessible (including war areas like Palmyra), and even travel through time, like going back to 16th century Edinburgh. Moreover, in close relation with the capacities of interactivity and creation, digital platforms are nowadays able to empower the public with a leading role in their communication of cultural resources $[18,19]$. The passive dissemination of heritage has given way to active communication based on co-creation, supporting effective preservation-related tasks-such as custom cultural learning, decision-making, and planning and design-if they are fully accepted by heritage managers in the transition to new models of site management.

Computer gaming has become one of the most popular streams in digital communication, broadly used not only by children and youths (over $70 \%$ of which play computer games) but by the adult population as well [20], of whom almost $40 \%$ play videogames [21]. The usefulness of videogames beyond entertainment has been increasingly examined. Recent studies have demonstrated the ability 
of videogames to influence both well-being and cognitive progresses [22]. References [23,24] have proposed videogames as a channel of mood management (emotional regulation) through entertainment, explained through the theory of excitatory homeostasis. References $[25,26]$ demonstrated videogame capacity to satisfy basic psychological needs through immersive-motivational processes. As such, exploring the use of simulation videogames for heritage communication is increasingly relevant.

\subsection{Serious and Commercial Videogames Related to Cultural Heritage}

Developments of prototypes for the better integration of virtual environments, speakers, and local and remote audiences has been the focus of recent research on heritage communication, which confirms the capacities of videogames for hosting a common-interactive space where actors and the environment converge [14]. The game-design principle has also been purposely integrated in the development of mobile Virtual Reality (VR) and Augmented Reality (AR) interfaces, looking to provide personalized and location-adapted solutions for $\mathrm{CH}$ dissemination $[27,28]$. Its usability and acceptance have been effectively studied by [29,30], confirming the existence of a large audience of educators and communicators aiming for the integration of gaming principles in VR and AR communication products, and improving the user's experience in edutainment scenarios and games. New questions arise, especially on the appropriateness of digital representation and communication of $\mathrm{CH}$ technologies (from reliable documentation technologies to Virtual Reality solutions) in the representation and communication of $\mathrm{CH}$ [15].

Videogames designed to teach or complement learning processes with a defined desirable outcome are framed within the serious-games (SG) movement [31-33]. Simulation SGs in cultural heritage are mainly developed by and for cultural and educational institutions: Museums, exhibitions, schools, among others, and are commonly unreleased to the wider public [34]. While these products are intended to fulfil specific needs, in general they have a considerable lack of mechanisms to engage the public at large, and especially to turn it into a "creator of knowledge" rather than a passive receiver of information [35]. Pedagogical structures are mainly focused on reaching educational milestones through typical mechanisms of extrinsic motivation: Awarding, giving qualifications, suggesting playing, among others.

However, some "serious" limitations arise from wider use of simulation SG. First, the unbalanced relation of extrinsic and intrinsic motivations, with the predominance of the first as the motor behind the use of serious games, has been targeted as one of the major motives to frustrate interest, engagement, and enjoyment $[25,36]$. Second, compared to commercial games, simulation SG have significantly lower budgets in terms of their production and development $[37,38]$. This has a direct impact not only on the fidelity of their graphics but also in the flexibility of the narrative structure and the learning curve. However, it is not only non-leisure purpose games that can achieve educative and cultural objectives [39]. It is possible to incorporate values of a "serious" nature into simulation videogames designed with entertainment as their main motivation [40].

The idea of reusing videogames for serious purposes essentially takes advantages of the already-built game engines, the diffusion and marketing structures linked with those games, the allegiance of large user communities, and the capacity to interact in complex 3D scenarios.

In the last few years, several commercial games have been the focus of interest by cultural and educational institutes and have been linked (with different degrees of integration) on projects with purposes beyond entertainment. Table 1 shows a list of videogames that have been used beyond entertainment, ordered by its published entries in the peer-reviewed literature database SCOPUS. Searching criteria were: Name of the videogame name included in the title, and paper published within the last five years (data retrieved on 1 June 2019). 
Table 1. Summary of selected commercial solutions based on their use beyond entertainment.

\begin{tabular}{|c|c|c|}
\hline Video Game & No. of Entries & Description + Uses beyond Entertainment \\
\hline Minecraft & 118 & $\begin{array}{l}\text { Developed by Mojang (currently owned by Microsoft), this videogame has been } \\
\text { largely used as an education and communication vehicle in cultural projects. } \\
\text { Since 2015, the Tate Gallery has recreated in Minecraft some of its most } \\
\text { well-known paintings [41], allowing players to delve into the real-life places } \\
\text { these selected paintings represent (Figure 1). Project Value, conducted from } \\
\text { Leiden University in 2015, attracted the attention of archaeologists and historians } \\
\text { in the use of Minecraft not only for public outreach and education, but for } \\
\text { research on evidence-finding [42]. Project consisted on co-rebuilding the recently } \\
\text { destroyed Temple of Bel, in Palmyra, based on 2D maps, and included an eager } \\
\text { cohort of } 40 \text { people. }\end{array}$ \\
\hline $\begin{array}{l}\text { Assassin's } \\
\text { Creed }\end{array}$ & 14 & $\begin{array}{l}\text { Developed by Ubisoft, this videogame is set in a semi-open environment. It } \\
\text { highlights a graphically engaging representation, linking both built environment } \\
\text { and narrative. } \\
\text { Assassin's Creed has been re-used as reference for subjects of History in different } \\
\text { education levels [43]. The game was also studied as classroom learning tool for a } \\
\text { large sample of high school students [44]. }\end{array}$ \\
\hline Second Life & 13 & $\begin{array}{l}\text { Claimed not to be a videogame by its developer, Linden Lab, this virtual world } \\
\text { allows the virtual representations of users, and the exploration and interaction } \\
\text { with the built environment. } \\
\text { SL has been applied on the development and evaluation of learning } \\
\text { environments, exploring the capacities to host group work and peer to peer } \\
\text { interaction [45]. Universities of Ioannina and Patras (Greece) joined efforts to } \\
\text { take advantage of Second Life for STEM education objectives, specifically in } \\
\text { problem-based physics learning activity [46]. }\end{array}$ \\
\hline Terraria & 1 & $\begin{array}{l}\text { This Sandbox model videogame, developed by Re-logic, features digging, } \\
\text { fighting, and building in a 2D environment. Terraria has supported studies on } \\
\text { human behavior [47] based on its capacities of interaction between character and } \\
\text { virtual game world. Despite its limited 2D representation, there is large informal } \\
\text { integration of Terraria in the classroom, documented thought High School and } \\
\text { University blogs and forums (e.g., https: } \\
\text { //www.reddit.com/r/Terraria/comments/5mzxqs/terraria_in_the_classroom/). }\end{array}$ \\
\hline Unearthed & 1 & $\begin{array}{l}\text { Developed by Semaphore, its release was criticized by videogame experts and } \\
\text { users because of its frequently broken gameplay mechanics, and bulky } \\
\text { animations. However, its capacity to link game narrative and historical events } \\
\text { has risen attention for its reuse beyond entertainment. Its reliable source of } \\
\text { information when setting the environment has promoted its analysis as potential } \\
\text { resource for the study of history [48]. Since it is the singular case of an } \\
\text { autochthonous Arab-developed videogame, it has been considered on its efforts } \\
\text { to demonstrate the multiculturalism within the Arab identity [49] }\end{array}$ \\
\hline
\end{tabular}

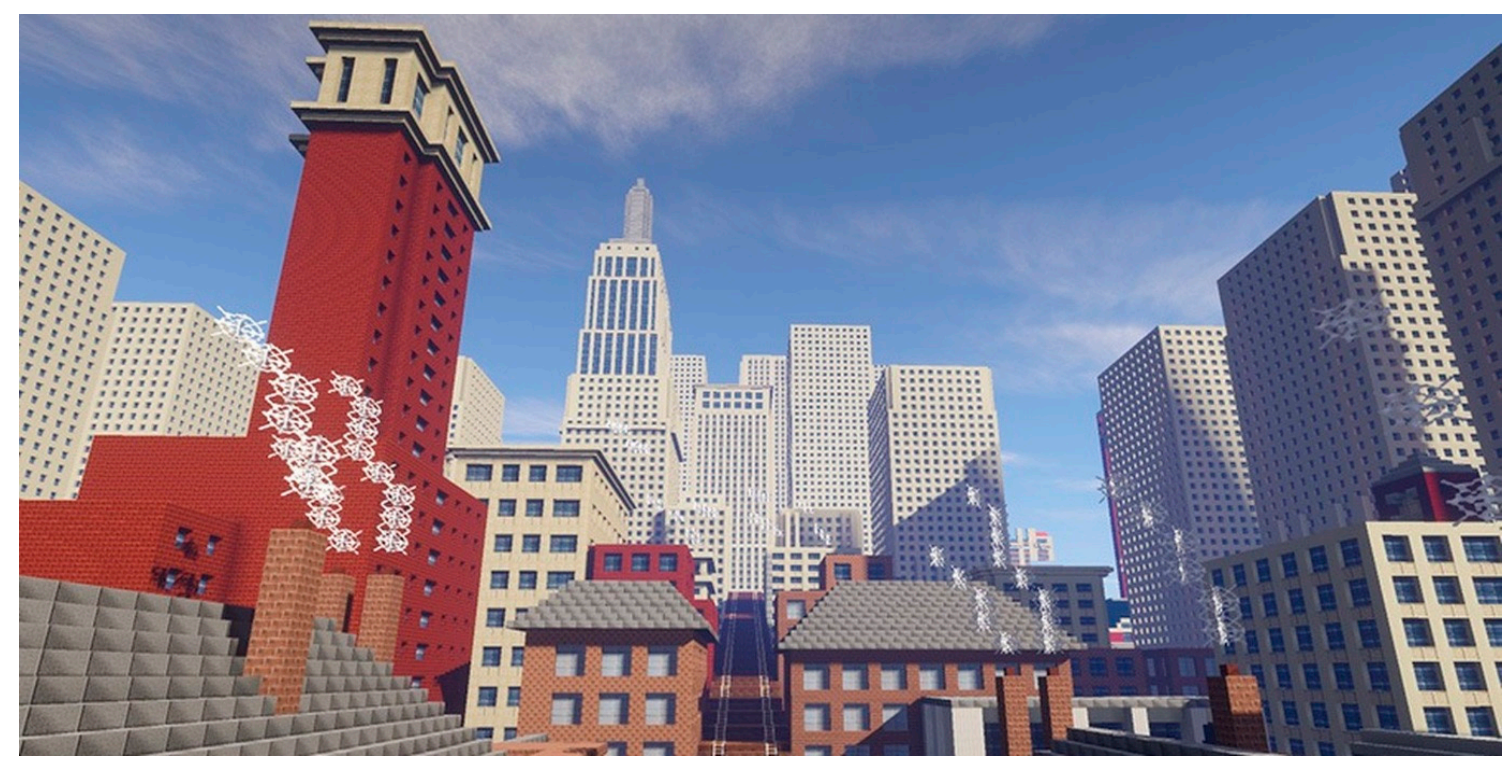

Figure 1. Representation of artworks in a Minecraft environment: "Soul of the Soulless City", by Christopher Nevinson [41]. 


\subsection{Simulation Videogames for Heritage Communication}

The opportunity to reuse commercial simulation videogames for cultural heritage communication becomes a possibility when videogames have the capacity (i) to foster game reengaging in a free-choice period through immersive mechanisms; (ii) to satisfy psychological needs and thus affect players' well-being through intrinsic motivation; and (iii) to accurately represent the historical built environment and its interactions to fit the principle of architectonic likelihood [50,51].

i. Immersion: Capacity to Foster Game Reengaging in a Free-Choice period. The linkage of players and our built environment through videogames is sustained by the capacity to provide immersive experiences. The illusion of non-mediation between players and content provides a strong sense of presence $[52,53]$. Studies such as $[54,55]$ have defined that a system is more likely to be immersive depending on in its capacity of graphic representation. However, the immersive dimension, as examined specifically for a virtual context by [56], requires graphic representations to be complemented with the emotional and narrative elements of the game world. These elements are not only directly linked with visual perception but also with the capacity of videogames to hold flexible stories, adapting to the players characteristics and interests (from gender and age segmentation to personalized content adaptation based on Artificial Intelligence algorithms $[57,58]$.

ii. Intrinsic motivation: Capacity to Satisfy Psychological Needs and Thus Affects players' well-being. Co-linear to the sense of presence is motivation, defined as the disposition to strive for a certain kind of satisfaction or desire [7,59]. Within the self-determination theory (STD) [60], motivations are classified as extrinsic and intrinsic, and represent the difference between "playing because you want to" (intrinsic) versus "playing because you must" (extrinsic). Factors that influence extrinsic motivation such as rewards, pressures, or evaluations [25] are mainly set externally in controlled environments to access desired end states or avoid aversive ones [26]. In this paper, we limit our analysis to intrinsic motivation.

The components defining intrinsic motivation are based on the human need to reach inherent satisfaction, and all these components directly contribute to human physical and psychological well-being and preference for future play. Several studies, among which $[61,62]$ concur on videogame capacity to satisfy three fundamental human needs:

- Competence, as the need for challenges and efficacy. Videogames have evolved to empower players with the capacity to act in the real-world by providing gaming experiences with flexible challenges, steady positive feedback, and game controls readily able to be mastered.

- Autonomy, as the need for players to commit themselves to a particular course of action (volition) and to create and direct actions for a given purpose (personal agency). Over time, videogame developers have broadened game designs and environments to increase the dimension of personal initiative by providing flexibility of goals, increasing the sense of choice and freedom in game actions.

- Relatedness, as the need to connect with others, fostering social interaction. Closely related with the arrival of the internet, videogames are increasingly providing new platforms to gather players in a shared environment, providing the opportunity to compete and cooperate.

iii. Fidelity On Simulations: Capacity to Represent the Real-World (Historical Built environment) and its Interactions. Fidelity within the field of computational modelling is usually understood as the accuracy of the representation of an object of interest when compared to the real world. The concept has been primarily linked to the graphical (geometrical and radiometrical) accuracy of the represented scenario; however, studies such as [63-65] have proposed more effective ways to describe fidelity in simulations-translate the focus from a photorealistic representation to interactive and multidimensional data, and integrate real-world characteristics beyond the visible data. Fidelity, under this perspective, includes the concepts of functional characteristics, and the quality of data in terms of the characteristics and the richness of the narrative. 
In simulation videogames representing real-world scenarios, fidelity must describe the relevant features of the real-world model, with their attributes, and accurately represent the possible interactions and their consequences.

\section{Minecraft for Built Heritage Communication}

To efficiently communicate our built heritage through videogames, we need to find platforms that not only allow the representation of the built environment in an engaging way but also take into account the functional properties of the represented elements and allow direct input from players [66]. As described in Section 2.1, there are several commercial solutions with the capacity to represent heritage environments while fostering player interaction. We have selected the videogame Minecraft to conduct this analysis due the volume of attention given to it by the scientific community (order on Table 1) especially in the area of cultural heritage, and the following essential capacities: Multiplayer mode, World Co-creation by users, and Operability in mobile and desktop devices.

Minecraft is an open-ended and multiuser virtual game (MMVE). With more than 176 million copies and 91 million active players in 2018 [67], Minecraft has become the best-selling game of all time [68], and the most viewed game in the platform YouTube [69]. This sand-box game, with the capacity to physically represent natural and built environment in 3D, can be played on desktop, consoles, and mobile devices. Its design is based on peer-to-peer architecture (P2P), allows independence on centralized servers [70] which let users host and share their own developments. Minecraft has implemented the possibility of modifying the game script according to the player's decisions and to do it collaboratively. This empowers the public with a leading role (as storytellers), while allowing a stronger connection between game narratives and personal and cultural values [11].

Minecraft, based on Lightweight Java Game Library (LWJGL) framework, does not require any programming skills for content creation and game script implementation. This minimum investment becomes especially relevant when targeting the representation of complex three-dimensional virtual environments, where modelling has been recognized as a highly specialized and time-consuming task [71]. Moreover, by being based on OpenGL and OpenAL, Minecraft uses parallel processing to improve speed and lower CPU overhead, while it can be coded using a variety of languages, including Java C, C++, among others. Compared to other game engines such as Unity and Unreal, with a steeper learning curve, Minecraft offers a framework easily manageable by educators, artists, and cultural communicators [72].

Minecraft has been increasingly taken into wider usage beyond entertainment, as shown in Figure 1. Relevant publications have demonstrated the potential of Minecraft as a tool for teaching a wide range of subjects from mathematical concepts to geography [73]. Studies have also shown Minecraft's capacity to embed information literacy skills into formal and informal environments [74], as well as the support that Minecraft provides for new digital communities [75].

While scientific studies [73,76] and hands-on projects [77,78] have explored the educational capacity of Minecraft and its potential to engage with the wider public, in the context of heritage communication there is no specific analysis linking Minecraft's capacity to represent the built heritage environment with its potential and limitations in technical and functional terms. However, previous investigations have dealt with its voxel-based representation nature, highlighting that low-resolution in Minecraft simplifies the gameplay mechanics and softens the users' learning curve [79], turning the videogame into a suitable tool for a wide range of different areas, such as education, urban planning, computer arts, or chemistry [80].

Based on the criteria defined in the previous section, to effectively use commercial simulation videogames for $\mathrm{CH}$ communication, in the following subsection we analyze the feasibility of the videogame Minecraft for this specific purpose.

i. Analysis of Immersion in Minecraft. Minecraft immersion is achieved primarily by a balanced relationship in the freedom of decision-making, the openness of path finding, and the autonomy in motion control. 
These interrelations respond to the immersion within the illusion of intelligence $[37,60]$ and soften the learning curve [70].

In terms of sense of agency, Minecraft is a sandbox game where there are no physical limits and no constraints in terms of rules or instructions. The freedom experienced in Minecraft has proved to be one of the key elements fostering both immersion and creativity [81]. Freedom of movement during game play is linked to a variety of in-game motions such as walking, running, jumping, and the ability to fly (Figure 2).

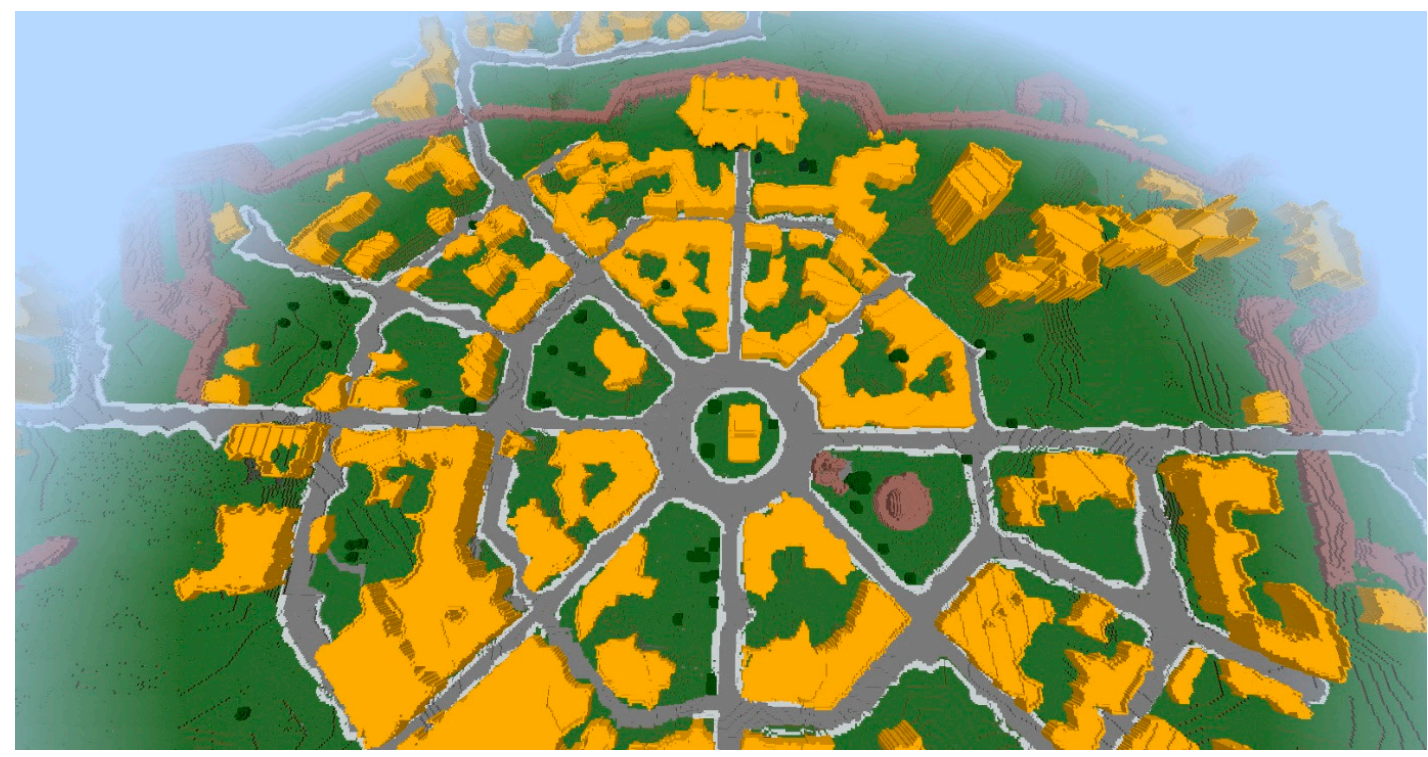

Figure 2. Character flying on a Minecraft city (self-created Minecraft world representing Hamina Fortress, Finland).

In terms of environmental representation, Minecraft's Lego-like scenarios are balanced with a wide variety of items, elements, and materials. The rich and complex scenarios and situations allow players to associate visual perceptions with complex narratives.

Finally Minecraft has the capacity to customize the game through mods (short for modifications), packages that modify the original programming code of the game, to transform the way the game looks and behaves. Among the mods that specifically enhance the physical, narrative, and emotional elements are "Smart Moving", which brings new motion modes such as crawl, climb, slide, swim, dive, and move freely, and "Enviro Mine", which introduces everyday life conditions such as temperature (heat stroke and hypothermia), hydration, air quality, and food spoiling.

ii. Internal Motivation in Minecraft.

a. Need for Competence. One of the main concerns of videogame developers continues to be the achievement of a correct balance between the player skills and the game's challenges. In the case of Minecraft, the sense of efficacy is promptly achieved by the reasonable relationship between the wide range of activities available; the effort expended in basic tasks such as moving, crafting, exploring; and the tangible results of those actions (e.g., built a house, farm the land, etc.).

New competences are not only available to expert players. It is possible to start playing Minecraft without any prior knowledge of the game. The basic control for motion together with a rule-based system, simulating real-world logic, allows players to steadily master the game and to move through skill-graded challenges. 
b. Autonomy Need. Minecraft is a sandbox (free-roaming) game, providing multiple opportunities of action without restrictions in terms of time limits, checkpoints, or locked areas. The non-linear nature of Minecraft, in contrast to a progression-style game, allows players to have full access to the virtual world while having total freedom in in-game choices. This is complemented by the influence of action, affecting both the story level and the virtual world, giving as a result the feeling of "being in control of the game" [54,57]. Moreover, the self-authorship in Minecraft is carried to a higher level than conventional sandbox videogames. Players are not only able to shape the game's narrative but can modify (re-code) the game script according to their interests or implement pre-built packages to customize their experiences.

c. Relatedness Need. The capacity of Minecraft to be played in single and multi-player mode provides a strong opportunity for engaging in social interactions and for the creation of virtual communities. Contrary to videogames with solely competitive multi-player modes, Minecraft multi-player mode allow users to play in a cooperative form (co-op). This feature enables teammate players from all around the world to share and cooperate towards a common goal.

The Minecraft developer community has been actively working on developing new ways to promote peer communications. Recently, several "Voice over Internet Protocols" (VoIP) have been adapted to make them able to be efficiently embedded in Minecraft Servers, allowing both performative and verbal communication during Minecraft experiences. While early collaborative games were hosted by university computer mainframes, Minecraft not only provides its own multi-player platforms (Minecraft Realms) but also allows users to host and share virtual worlds in their own computers. This, together with the capacity of customizing the hosted virtual worlds, and with the support of dedicated alternative communication platforms such as WebForum and Chat channels, has propelled the establishment of Minecraft communities around the world, both virtually and in-person. The association based on game preferences and mutual cultural interest currently empowers these communities with the ability to forge long-term social bonds.

iii. Fidelity On simulation. Minecraft balances a considerable capacity to represent and combine complex elements of the real world with the reduction of the geometrical complexity of that world, defined by a certain level of abstraction. ${ }^{1}$ The level of abstraction in Minecraft, in terms of built environment representation, is characterized by a varied selection of materials (including vegetation elements and items) commonly found in the real-world. A voxelated environment, consisting of cubes of $1 \mathrm{~m}^{3}$, together with the addition of texture and metadata of a wide range of materials and objects, turns Minecraft into a powerful channel to represent both geometry and the qualitative properties of the built environment, bringing together both the real site being represented and the unique look of the platform, which immediately brings to the viewer the idea of play, while providing an opportunity for learning.

Moreover, while the geometrical representation of the environment is simplified and transformed, the "natural" laws that govern the Minecraft world fit the complex logic of the real-world. Concepts such as day/night, gravity, photosynthesis, hardness of material, among others, allow players to recognize and use Minecraft's functional characteristics for a more faithful gaming experience.

\section{Discussions}

Simulation videogames are today an essential tool to communicate $\mathrm{CH}$ values, providing platforms that promote edutainment in a society that is increasingly digital. Not only the games with serious purposes are capable to effectively communicate $\mathrm{CH}$ values, since commercial games have also been

1 The term "level-of-abstraction", and not "Level of detail (LoD)", is used because LoD is closely related to the scale concept, and the scale in the videogame Minecraft is invariably 1:1. 
used with a broader perspective, representing real-world information beyond entertainment. However, they do not always fit the specific needs of $\mathrm{CH}$ communication especially in terms of scientifically and realistically conveying historical data. Currently, the design process of serious simulation games does not always include a strategy to satisfy psychological needs, especially those related with internal motivation and game-engagement fosterage. Without solutions and criteria that guide us in the selection and assessment of videogames for the purpose of $\mathrm{CH}$ communication, we are left with inadequate knowledge, which leads to a misuse of videogames for communication and a weak base for further developments of simulation games on this field.

This article provides a critique of the digital culture in heritage communication, and a review on the use of serious and commercial videogames in $\mathrm{CH}$. In particular, it is argued that not all simulation videogames have the capacity to transmit heritage information efficiently. Hence, it has defined and described those capacities that foster game reengaging, satisfy psychological needs, affect player well-being, and accurately represent real-world features. The resulting considerations help in framing and identifying characteristics for the selection, assessment, and design of simulation videogames in the context of $\mathrm{CH}$. Based on this analysis, the paper examines the MMVe platform Minecraft, a widely used simulation videogame, in terms of immersion, internal motivation, and fidelity on simulation. The results of the analysis support previous scientific affirmations of its usability beyond entertainment—as a tool against functional illiteracy [73], a social binder [74], among others. This analysis endorses Minecraft's capacity to communicate cultural heritage values while satisfying basic psychological needs, promoting the game's replay-ability and accurate representation of the complexity and relations of real-world elements. This highlights the capacity of Minecraft as an optimal platform to address the communication of cultural heritage values, even if care with fidelity in the representation of the integral heritage must be present in the developers of each world. This paper provides an insight of the videogame in terms of immersion, motivation, and psychological satisfaction of needs, that can be useful for scholars and researchers not only interested in the educational use of Minecraft, but also in cognitive analysis and videogame design strategies.

Future research designs may benefit from the systematic analysis of specific case studies where Minecraft has been applied to Cultural Heritage communication, including the analysis of strategies of engagement, user perception of the story, as well as their suggestions for making it more effective.

Additionally, this paper did not analyze the processes and solutions on the transformation of three-dimensional real-world information and its semantics into Minecraft. Thus, our assessments in videogame fidelity needs a study-in-detail including geometrical and semantical comparison of real-world information and as-build Minecraft data. Still, it aims to provide a strong theoretical base with which to analyze this game and support its use in $\mathrm{CH}$ communication, especially for built heritage. As such, it is in line with a practice that is becoming increasingly common and helps connect with audiences that, through play, get to know more about their heritage. Minecraft promotes itself as a game to "position blocks and go on adventures", and the discovery of our heritage may be one of the greatest adventures we have within our reach.

Author Contributions: J.G.-F. performed original draft, conceptualization, investigation, and methodology; and contributed to the funding acquisition. L.M. performed conceptualization, investigation and writing-review and editing.

Funding: This research was funded by H2020 Marie Skłodowska-Curie Actions, grant number 747046.

Acknowledgments: The research leading to these results has received funding from the Research and Innovation Framework Programme (Marie Curie Actions) of the European Union's Horizon 2020 Framework Programme H2020-MSCA-IF-2016, project 3D-SMoHC no. 747046.

Conflicts of Interest: The authors declare no conflict of interest.

\section{References}

1. Fontal, O. La Educación Patrimonial: Teoría y Práctica en el Aula, el Museo e Internet, España, ed.; Trea: Gijón, Spain, 2003. 
2. Calaf, R. Investigación en didáctica del Patrimonio y museografía didáctica. HerEMus Herit. Museography 2009, 1, 115-121.

3. Gómez-Redondo, C.; Fontal, O.; Ibáñez-Etxeberria, A. The use of ICT for heritage recognition and identization processes in contemporary art. Artnodes 2016, 17, 52-63. [CrossRef]

4. Etxberria, F. Videojuegos, Consumo y Educación; Universidad de Salamanca: Salamanca, Spain, 2008; Volume 9, pp. 14-28.

5. Garcia-Fernandez, J. Chapter II: An Urgent Problem in an Emerging Field: Immersion of the Architect in Heritage Education, in Digital Culture for the Enhancement of Heritage Value: Generation of Heritage Products with and Educational Scope. Ph.D. Thesis, University of Valladolid, Valladolid, Spain, 2014; pp. 82-112.

6. Dalisay, F.; Kushin, M.; Yamamoto, M.; Liu, Y.; Skalski, P. Motivations for game play and the social capital and civic potential of video games. New Media Soc. 2015, 17, 1399-1417. [CrossRef]

7. Przybylski, A.; Rigby, S.; Ryan, R. A Motivational Model of Video Game Engagement. Rev. Gen. Psychol. 2010, 14, 154-166. [CrossRef]

8. Cuenca López, J.; Martín, M. La Resolución de Problemas en la Enseñanza de las Ciencias Sociales a Través de Videojuegos. Iber: Didáctica De Las Cienc. Soc. Geogr. Hist. 2010, 63, 32-42.

9. Enqvist, J. The new heritage: a missing link between finnish archaeology and contemporary society? Fennosc. Archaeol. 2014, 31, 101-123.

10. Smith, L. Uses of Heritage; Routledge: Oxon, UK, 2006; p. 351.

11. Atalay, S. Community-Based Archaeology: Research with, by, and for Indigenous and Local Communities; University of California Press: Berkeley, CA, USA; Los Angeles, CA, USA; Boston, MA, USA, 2012; p. 312.

12. Gruber, M. The Role of E-Learning in Arts and Cultural Heritage Education. In Kreativität und Innovationskompetenz im Digitalen Netz; Hornung-Prähauser, V., Luckmann, M., Eds.; Salzburg Research: Salzburg, Austria, 2009; pp. 343-350. ISBN 978-3-902448-14-9.

13. Ferreira, S.M.; Gouin-Vallerand, C. Game based learning: A case study on designing an educational game for children in developing countries. In Proceedings of the 8th International Conference on Games and Virtual Worlds for Serious Applications, VS-Games, Barcelona, Spain, 7-9 September 2016. Article number 7590350.

14. Champion, E.M. A 3d pedagogical heritage tool using game technology. Mediterr. Archaeol. Archaeom. 2016, 16, 63-72. [CrossRef]

15. Liritzis, I.; Al-Otaibi, F.M.; Volonakis, P.; Drivaliari, A. Digital technologies and trends in cultural heritage. Mediterr. Archaeol. Archaeom. 2015, 15, 313-332. [CrossRef]

16. Nikonova, A.A.; Biryukova, M.V. The Role of Digital Technologies in the Preservation of Cultural Heritage. Museol. Cult. Herit./Muzeol. Kult. Dedicstvo 2017, 5, 169-173.

17. Portalés, C.; Rodrigues, M.F.; Lozano, J.S.; Pagán, E.A.; Gonçalves, A.R. Digital Cultural Heritage, Multimodal Technologies and Interact. Multimodal Technol. Interact. 2018, 2, 58. [CrossRef]

18. Abubakar, J.A.; Jahnkassim, P.S.; Mahmud, M. Effects of interactive digital media on architectural heritage learning. J. Teknol. 2016, 78, 41-48. [CrossRef]

19. Burton, J. News-Game Journalism: History, Current Use and Possible Futures. Aust. J. Emerg. Technol. Soc. 2005, 3, 87-99.

20. Salmon, J.; Dolan, S.; Drake, R.; Wilson, G.; Klein, R.; Eskes, G. A survey of video games preferences in adults: Building better games for older adults. Entertain. Comput. 2017, 21, 45-64. [CrossRef]

21. AEVI. Anuario De La Industria Del Videojuego; AEVI: Madrid, Spain. Available online: http://www.aevi.org.es/ web/wp-content/uploads/2017/06/ANUARIO_AEVI_2016.pdf (accessed on 20 June 2017).

22. Gnambs, T.; Appelb, M. Is Computer Gaming Associated with Cognitive Abilities? A population study among German adolescents. Intelligence 2017, 61, 19-28. [CrossRef]

23. Park, Y. The Effects of Media Interactivity on Mood Regulation: An. Experimental Study. Ph.D. Thesis, Florida State University, Tallahassee, FL, USA, 2008.

24. Bryant, J.; Davies, J. Selective exposure to videogames. In Playing Videogames Motives, Responses, and Consequences; Routledge: New York, NY, USA, 2006; pp. 210-229.

25. Deci, E.L.; Koestner, R.; Ryan, R.M. A meta-analytic review of experiments examining the effects of extrinsic rewards on intrinsic motivation. Psychol. Bull. 2000, 125, 627-668. [CrossRef] 
26. Ryan, R.; Deci, E. Intrinsic and Extrinsic Motivations: Classic Definitions and New Directions. Contemp. Educ. Psychol. 2000, 25, 54-67. [CrossRef]

27. Koutromanos, G.; Sofos, A.; Avraamidou, L. The use of augmented reality games in education: A review of the literature. Educ. Media Int. 2015, 52, 253-271. [CrossRef]

28. Vosinakis, S.; Avradinis, N.; Koutsabasis, P. Dissemination of Intangible Cultural Heritage Using a Multi-agent Virtual World. In Advances in Digital Cultural Heritage; Ioannides, M., Martins, J., Žarnić, R., Lim, V., Eds.; Lecture Notes in Computer Science; Springer: Cham, Switzerland, 2018; Volume 10754, pp. 197-207.

29. Ekonomou, T.; Vosinakis, S. Mobile augmented reality games as an engaging tool for cultural heritage dissemination: A case study. Sci. Cult. 2018, 4, 97-107.

30. Deliyiannis, I.; Papaioannou, G. Augmented reality for archaeological environments on mobile devices: A novel open framework. Mediterr. Archaeol. Archaeom. 2014, 14, 1-10.

31. Griffiths, M. The educational benefits of videogames. Educ. Health 2002, 20, 47-51.

32. Marsh, T. Serious games continuum: Between games for purpose and experiential environments for purpose. Entertain. Comput. 2011, 2, 61-68. [CrossRef]

33. Wendel, V.; Gutjahr, M.; Gobel, S. Designing collaborative multiplayer serious games Escape from Wilson Island-A multiplayer 3D serious game for collaborative learning in teams. Educ. Inf. Technol. 2013, 18, 287-308. [CrossRef]

34. Anderson, E.; Mc Loughlin, L.; Comninos, P. The case for research in game engine architecture. In Proceedings of the Conference on Future Play: Research, Play, and Share, Toronto, ON, Canada, 3-5 November 2008; pp. 228-231.

35. Mortara, M.; Catalano, C.; Belloti, F.; Fiucci, G.; Houry-Panchetti, M.; Petridis, P. Learning cultural heritage by serious games. J. Cult. Herit. 2014, 15, 318-325. [CrossRef]

36. Brockmyer, J.; Fox, C.; Curtiss, K.; McBroom, E.; Burhart, K. The development of the Game Engagement Questionnaire: A measure of engagement in video game-playing. J. Exp. Soc. Psychol. 2009, 45, 624-634. [CrossRef]

37. Anderson, E.; McLoughlin, L.; Liarokapis, F.; Peters, C.; Patridis, P.; Freitas, S. Developing serious games for cultural heritage: A state-of-the-art review. Virtual Real. 2010, 14, 255-275. [CrossRef]

38. Anderson, E.; Mc Loughlin, L.; Watson, J.; Holmes, S.; Jones, P. Choosing the Infrastructure for Entertainment and Serious Computer Games-A Whiteroom, Benchmark for Game Engine Selection. In Proceedings of the 5th International Conference on Games and Virtual Worlds for Serious Applications (VS-GAMES), Dorset, England, UK, 11-13 September 2013; pp. 1-8.

39. Garcia-Fernandez, J. Chapter VI: Study of actors: the public, lead role. Digital Culture for the Enhancement of Heritage Value: Generation of Heritage Products with and Educational Scope. Ph.D. Thesis, University of Valladolid, Valladolid, Spain, 2014; pp. 243-262.

40. Geraci, R.; Recine, N. Enlightening the Galaxy: How Players Experience Political Philosophy in Star Wars: The OldRepublic. Games Cult. 2014, 9, 255-276. [CrossRef]

41. Romano, A. You Can Visit One of Britain's Most Famous Art Galleries in Minecraft. The Daily Dot. Available online: https:/www.dailydot.com/parsec/minecraft-tate-museum-exhibit/ (accessed on 20 December 2018).

42. Politopoulos, A. The VALUE project: Video Games and Archaeology at Leiden University, V:6. 10 June 2017. Available online: http://www.asor.org/anetoday/2017/06/value-project (accessed on 16 May 2018).

43. Molina, E.C. A pedagogical proposal to support the teaching of history with audiovisual content, including video game advertising: The example of Assassin's Creed IV: Black Flag and Privateer Amaro Pargo. In Advances in Communications and Media Research; Nova Science Publishers: Hauppauge, NY, USA, 2017; Volume 12, pp. 146-164.

44. Karsenti, T.; Bugmann, J.; Parent, S. Can Students Learn History by Playing Assasin's Creed? CRIFPE: Montreal, QC, Canada, 2019.

45. De Lucia, A.D.; Francese, R.; Passero, I.; Tortora, G. Development and evolution of a virtual campus on second life: The case of second DMI. Comput. Educ. 2008, 52, 220-233. [CrossRef]

46. Vrellis, I.; Papachristos, N.; Bellou, J.; Avouris, N.; Mikropoulos, T. Designing a Collaborative Learning Activity in Second Life An exploratory study in physics. In Proceedings of the 10th IEEE International Conference on Advanced Learning Technologies ICALT10, Sousse, Tunisia, 5-7 July 2010; pp. 210-214. 
47. Lim, J.S. Using think-aloud protocol in looking at the framing of one's character with a case study on terraria. In Proceedings of the 10th International Conference on Virtual Worlds and Games for Serious Applications, VS-Games 2018, Wurzburg, Germany, 5-7 September 2018. Article number 8493446.

48. Majed, B.; Darren, M. Analysing cultural heritage and its representation in video games. In Proceedings of the 2015 DiGRA International Conference Digital Games Research Association (DiGRA 15), Lüneburg, Germany, 14-17 May 2015; Volume 12. Article number 124294.

49. Alfaraj, B. Arab Gamers: An. Identity Inclusivity Study. Master's Thesis, Drexel University, Philadelphia, PA, USA, 2016.

50. Bellotti, F.; Berta, R.; Cardona, R.; De-Gloria, A. An architectural approach to efficient 3D urban modeling. Comput. Graph. 2011, 35, 1001-1012. [CrossRef]

51. Bellotti, F.; Berta, R.; De-Gloria, A.; D’Ursi, A.; Fiore, V. A serious game model for cultural heritage. J. Comput. Cult. Herit. 2012, 5, 17-27. [CrossRef]

52. Saari, T. Modeling Positive Experiences in Human-Computer Interaction. In Proceedings of the 2nd Conference on Human System Interactions (HSI), Catania, Italy, 21-23 May 2009; pp. 528-535.

53. Lombard, M.; Ditton, T. At the heart of it all: The concept of presence. J. Comput.-Mediat. Commun. 1997, 3, 1-46. [CrossRef]

54. Slater, M.; Wilbur, S. A Framework for Immersive Virtual Environments (FIVE): Speculations on the Role of Presence in Virtual Environments. Presence Teleoperators Virtual Environ. 1997, 6, 603-616. [CrossRef]

55. McMahan, R.; Bowman, D.; Zielinski, D.; Brady, R. Evaluating Display Fidelity and Interaction Fidelity in a Virtual Reality Game. IEEE Trans. Vis. Comput. Graph. 2012, 18, 626-633. [CrossRef]

56. Weinstein, N.; Przybylski, A.K.; Ryan, R.M. Can nature make us more caring? Effects of immersion in nature on intrinsic aspirations and generosity. Personal. Soc. Psychol. Bull. 2009, 35, 1315-1329. [CrossRef]

57. Georgiou, T.; Demiris, Y. Adaptive user modelling in car racing games using behavioural and physiological data. User Model. User-Adapt. Interact. 2017, 27, 267-311. [CrossRef]

58. Safadi, F.; Fonteneau, R.; Ernst, D. Artificial intelligence in video games: Towards a unified framework. Int. J. Comput. Games Technol. 2015, 5, 271296. [CrossRef]

59. Atkinson, J. Motivational determinant of risk-taking behavior. Psychol. Rev. 1957, 64, 359-372. [CrossRef]

60. Ryan, R.; Rigby, S.; Przybylski, A. The motivational pull of video games: A self-determination theory approach. Motiv. Emot. 2006, 30, 347-364. [CrossRef]

61. Ryan, R.; Deci, E. Self-determination theory and the facilitation of intrinsic motivation, social development, and well-being. Am. Psychol. 2000, 55, 68-78. [CrossRef]

62. Sheldon, K.M.; Filak, V. Manipulating autonomy, competence and relatedness support in a game-learning context: New evidence that all three needs matter. Br. J. Soc. Psychol. 2008, 47, 267-283. [CrossRef]

63. Gross, D.C. Report from the Fidelity Implementation Study Group. In Proceedings of the Spring Simulation Interoperability Workshop, Orlando, FL, USA, 14-19 March 1999. Article number 167.

64. Sauvé, L.; Renaud, L.; Kaufman, D.; Marquis, J. Distinguishing between games and simulations: A systematic review. J. Educ. Technol. Soc. 2007, 10, 247-256.

65. Liritzis, I.; Volonakis, P.; Vosinakis, S.; Pavlidis, G. Cyber-archaeometry from cyber-archaeology: New dynamic trends in archaeometric training and research. In Proceedings of the Second International Conference Virtual Archaeology, Saint Petersburg, Russia, 1-3 June 2015; pp. 38-40.

66. Calleja, G. Digital game involvement, A conceptual model. Games Cult. 2007, 2, 236-260. [CrossRef]

67. Watts, R. Minecraft's Player Count. Available online: https://www.pcgamesn.com/minecraft $/$ minecraftplayer-count (accessed on 4 June 2019).

68. Deason, R. Fwiz Reveals the Most Popular Game on YouTube and It's Not Fortnite. Available online: https://www.dexerto.com/gaming/fwiz-reveals-the-most-popular-game-on-youtube-andits-not-fortnite-166593 (accessed on 20 June 2019).

69. Yaden, J. Minecraft Has Become the Best-Selling Game of All Time. Available online: https://www. playstationlifestyle.net/2019/05/17/minecraft-best-selling-game-of-all-time/ (accessed on 18 June 2019).

70. Engelbrecht, H.A.; Schiele, G. Transforming Minecraft into a Research Platform. In Proceedings of the 11th Consumer Communications and Networking Conference, Las Vegas, NV, USA, 10-13 January 2014; pp. 257-262. 
71. Wünsche, B.; Keymer, D.; Amor, R. Sketch, click, plug and play: accelerated design of virtual environments by integrating multimedia and sketch content into game engines. In Proceedings of the 11th International Conference of the NZ Chapter of the ACM Special Interest Group on Human-Computer Interaction, Auckland, New Zealand, 8-9 July 2010; pp. 33-40.

72. Cho, O.; Kim, K.; Lee, S. Research about minecraft as interactive program for 3D virtual digital art. Int. J. Multimed. Ubiquitous Eng. 2015, 10, 395-400. [CrossRef]

73. Daly, E. Explore, create, survive. Sch. Libr. J. 2012, 58, 24-25.

74. Hill, V. Digital citizenship through game design in Minecraft. New Libr. World 2015, 116, 369-382. [CrossRef]

75. Niemeyer, D.; Gerber, H. Maker culture and Minecraft: Implications for the future of learning. Educ. Media Int. 2015, 52, 216-226. [CrossRef]

76. Barth-Maron, G.; Abel, G.; MacGlashan, J. Affordances as Transferable Knowledge for Planning Agents. In Proceedings of the Symposium Knowledge, Skill, and Behavior Transfer in Autonomous Robots, Arlington, VA, USA, 13-15 November 2014; pp. 2-8.

77. Shaw, E.; Tuan, M.; Phillips, R.; Reilly, E. PLAY Minecraft! Assessing secondary engineering education using game challenges within a participatory learning environment. In Proceedings of the ASEE Annual Conference, Indianapolis, IN, USA, 15-18 June 2014. Article number 8438.

78. Zhu, K.; Huen, M. Teaching and learning of Chinese history in minecraft: A pilot case-study in Hong Kong secondary schools. In Proceedings of the 16th International ACM Conference on Interaction Design and Children, Stanford, CA, USA, 27-30 June 2017; pp. 405-410.

79. Nebel, S.; Schneider, S.; Rey, G.D. Mining Learning and Crafting Scientific Experiments: A Literature Review on the Use of Minecraft in Education and Research. Educ. Technol. Soc. 2016, 19, 355-366.

80. Ekaputra, G.; Lim, C.; Eng, K. Minecraft: A Game as an Education and Scientific Learning Tool. In Proceedings of the Information Systems International Conference (ISICO), Bali, Indonisia, 2-4 December 2013; pp. $237-242$.

81. Dezuanni, M.; O'Mara, J. Impassioned learning and Minecraft. In Serious Play: Literacy, Learning and Digital Games; Routledge: New York, NY, USA, 2017; pp. 36-48.

(C) 2019 by the authors. Licensee MDPI, Basel, Switzerland. This article is an open access article distributed under the terms and conditions of the Creative Commons Attribution (CC BY) license (http://creativecommons.org/licenses/by/4.0/). 